Goldschmidt 2021 Abstract

https://doi.org/10.7185/gold2021.4158

\section{Triple Oxygen Isotopic Compositions of Ocean Water from Mariana Trench}

\section{YING LIN ${ }^{1,2}$, NANPING WU ${ }^{1}$, KAIWEN TA ${ }^{1}$, AMAELLE LANDAIS $^{3}$ AND XIAOTONG PENG ${ }^{1}$}

${ }^{1}$ Institute of Deep Sea Science and Engineering, Chinese Academies of Sciences

${ }^{2}$ University of California, Riverside

${ }^{3}$ LSCE - Institut Pierre Simon Laplace

Presenting Author: yinglin@ucr.edu

High precision triple oxygen isotope data on 40 water samples (5 to $10,923 \mathrm{~m}$ depths) collected from Mariana Trench at the vicinity of $10^{\circ} \mathrm{N} 140^{\circ} \mathrm{E}$ are reported in this study. The analyses yield mean values of $-0.084 \pm 0.224 \%$ o $(1 \sigma),-0.061 \pm 0.117$ $\%(1 \sigma)$ and $-17 \pm 5 \mathrm{ppm}(1 \sigma)$ for $\delta^{18} \mathrm{O}, \delta^{17} \mathrm{O}$ and $\Delta^{17} \mathrm{O}$, respectively. The range of $\delta^{18} \mathrm{O}(-0.480$ to $0.544 \%)$ is consistent with NASA Global Seawater Oxygen-18 database for Mariana Trench (Figure 1). The average $\Delta^{17} \mathrm{O}$ value of $-17 \mathrm{ppm}$ at Mariana Trench is statistically different from the average $\Delta^{17} \mathrm{O}$ value of $-5 \mathrm{ppm}$ for 38 water samples collected at depths of 2$5390 \mathrm{~m}$ from Atlantic, Pacific, Mediterranean, and northern Red Sea [1]. The slope of the three-isotope-plot, $\lambda$, of Mariana Trench water is $0.5206 \pm 0.0032$ (Figure 2), indicating kinetic diffusion including molecular diffusion and turbulent/eddy diffusion $\left(\theta_{\mathrm{k}}=\right.$ $0.5142)$ as the dominant processes in ocean body. The $\Delta^{17} \mathrm{O}$ of $17 \mathrm{ppm}$ is identical to the ocean steady-state isotope mass balance model prediction of modern ice-free world [2]. The fluxes associated with major geological processes controlling the total oxygen budget of the oceans via lithosphere-hydrosphere interactions from pioneering studies [3,4] would have to be modified significantly in order to obtain model predictions of seawater $\Delta^{17} \mathrm{O}=-4 \mathrm{ppm}$ for modern ice-free world and $\Delta^{17} \mathrm{O}=-$ $5 \mathrm{ppm}$ for modern world. The triple oxygen isotopic compositions of seawater from this study can contribute to the advancement of isotope thermometry based on mineral-water equilibrium, to the understanding of ocean isotope mass balance, and potentially contribute to the replenishment of international measurement standards based on ocean water.

[1] Luz and Barkan (2010), Geochim. Cosmochim. Acta. 74:6276-6286.

[2] Sengupta and Pack (2018), Chem. Geol. 495:18-26.

[3] Muehlenbachs (1998), Chem. Geol. 145:263-273.

[4] Muehlenbachs and Clayton (1976), J. Geophys. Res. $81: 4365$.
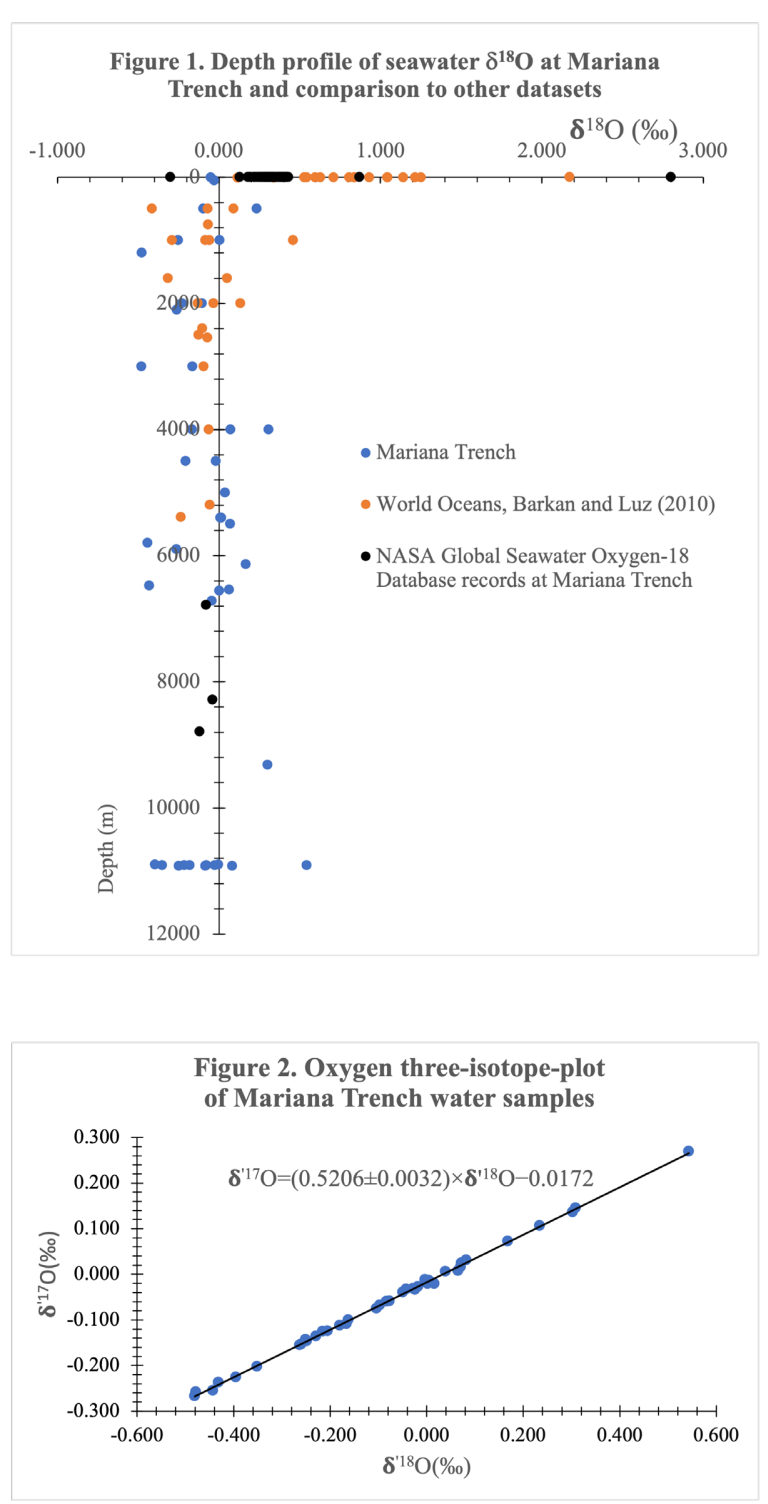